\title{
The working families' tax credit and some European tax reforms in a collective setting
}

\author{
Michal Myck · Olivier Bargain · Miriam Beblo · Denis Beninger · \\ Richard Blundell · Raquel Carrasco - Maria-Concetta Chiuri • \\ François Laisney • Valérie Lechene - Ernesto Longobardi • \\ Nicolas Moreau $\cdot$ Javier Ruiz-Castillo $\cdot$ Frederic Vermeulen
}

\begin{abstract}
A framework for simplified implementation of the collective model of labor supply decisions is presented in the context of fiscal reforms in the UK. Through its collective form the model accounts for the well known problem of distribution between wallet and purse, a broadly debated issue which has so far been impossible to model due to the limitations of the unitary model of household behavior. A calibrated data set is used to model the effects of introducing two forms of the Working Families' Tax Credit. We also summarize results of estimations and calibrations obtained using the same methodology on data from five other European countries. The results underline the importance of taking account of the intrahousehold decision process and suggest that who receives government transfers does matter from the point of view of labor supply and welfare of household members. They also highlight the need for more research into models of household behavior.
\end{abstract}

Keywords Collective models · Fiscal reforms · Household labor supply · Intrahousehold allocation

\author{
M. Myck $(\varangle) \cdot$ R. Blundell $\cdot$ V. Lechene \\ IFS, London, UK \\ e mail: MMyck@diw.de \\ M. Myck \\ DIW, Berlin, Germany \\ O. Bargain \\ IZA, Bonn, Germany \\ M. C. Chiuri · O. Bargain \\ CHILD, Turin, Italy \\ M. Beblo · D. Beninger - F. Laisney \\ ZEW, Mannheim, Germany \\ R. Blundell \\ UCL, London, UK
}

\author{
R. Carrasco · J. Ruiz Castillo \\ Universidad Carlos III, Madrid, Spain \\ E. Longobardi · M. C. Chiuri \\ Università di Bari, Bari, Italy \\ F. Laisney \\ BETA Theme, ULP, Strasbourg, France \\ V. Lechene \\ Wadham College, Oxford, England \\ N. Moreau \\ GREMAQ and LIRHE, Toulouse, France \\ F. Vermeulen . \\ Tilburg University, Tilburg, The Netherlands
}




\section{Introduction}

One of the major reforms of the UK Labour Government in the area of taxes and benefits directly affecting households was the introduction of the Working Families' Tax Credit (WFTC) in October 1999. The WFTC, an in work benefit for families with children, replaced the Family Credit, and like its predecessor was to be conditional on at least $16 \mathrm{~h}$ of paid work per week. The Government suggested that, in order to underline the con nection between payments and work, the WFTC would be paid via the pay packet. In effect, this aspect of the reform would constitute a redistribution of resources within households from '"purse to wallet', as it would mean paying the benefit to the main earner in households, rather than to the main carer as was the case with the Family Credit. It was finally decided to allow couples the choice of the identity of the recipient of the benefit, with a possibility of veto from the main carer. The controversy which led to this change is reminiscent of the discussions which surrounded the reform of the child benefit system in the UK in the late 1970s. In both cases, it was felt that the distribution of resources within households might impact on individual behavior and welfare. This has indeed been con firmed by empirical evidence on consumption patterns (e.g., Lundberg \& Pollak, 1996).

The standard unitary model of household labor supply (see for example Blundell \& Walker, 1986; Van Soest, 1995) does not allow for the analysis of the impact of redis tribution of resources between household members, as those are constrained by the structure of the model to have no effect on choices. In this setting, individual preferences and the possible strategic interactions between agents are obscured by the structure of the model and choices are made subject to a household budget constraint. This approach would therefore fail to show any difference between Family Credit and WFTC resulting from the redistribution of resources away from main carers (mostly mothers) and toward main earners (mostly fathers). In fact, this part of the reform was not considered in the simu lation of the WFTC conducted both by Blundell, Duncan, McCrae, and Meghir (2000), and Gregg, Johnson and Reed (1999).

The present paper builds on the methodology suggested in Frederic Vermeulen et al. (2006) to implement a collective model of labor supply with discrete choice. The approach assumes that some of the preferences can be retrieved by the observation of the behavior of single individuals while a marriage specific preference term and the bargaining rules are calibrated on observed labor supply of men and women in couples. The calibrated bar gaining rule is then estimated on a set of variables including the relative financial con tribution of wife and husband in household net income. In particular, one of the variables aims to capture the difference between giving the WFTC to the main carer versus giving it to the main earner. This way, the simulation of the WFTC reform does not only entail a change in budget constraints but also a potentially important effect on intrahousehold distribution due to the "purse to wallet" nature of the reform. In the present paper, we present the results on UK data and focus on the WFTC reform. Results for income tax and tax credit reforms for five other European countries are also summarized (for more results on UK reforms see Blundell, Lechene, \& Myck, 2002). 
Following the methodology presented in Vermeulen et al. (2006), we construct a data set for couples on the basis of a fully deterministic model with features of the collective framework. The reforms are simulated on the predicted data. For two variants of the WFTC reform, we compute the changes in relative power within couples and the changes in labor supply and welfare. Our findings suggest that who receives the money does matter. It turns out that individual utilities in couples depend on the earning potential of the members of the couple including variables relating to the fiscal system. The simulations also suggest that as a consequence of changing the bargaining power within couples, labor supply responses can be different depending on the precise nature of fiscal reforms.

The paper is organized as follows. We begin, in Section 2, with a description of the UK tax and benefit system. This is followed (Section 3) by a description of the data. Section 4 presents the theoretical effects of the reform. Section 5 analyzes the results of the reform simulations. Section 6 briefly reviews comparable results obtained from five other Euro pean countries, and Section 7 concludes.

\section{The tax and benefit system in the UK}

We describe the tax and benefit system in the UK in April 1998, which is the baseline for our exercise, as well as the October 1999 reform of in work transfers which we analyze. We first discuss personal taxation, then means tested benefits and in work transfers, and finally the stylized reform of in work transfers we model. We show how the pre reform tax and benefit system results in a rather striking budget constraint, where for a large pro portion of the low paid labor force, marginal tax rates are effectively close to $100 \%$ over a large range of hours.

\subsection{Personal taxation in the UK in $1998 / 99$}

The UK personal tax system is made of two major components income tax and National Insurance. Since the 1990 reform to the tax system, the income tax system has been based on annual individual assessment. Each taxpayer has a personal allowance of $£ 4,195$ $(€ 6,090) .{ }^{1}$ Depending on the level of income, the marginal tax rate applied is 20,23 or $40 \%$ (details in Table A1 in the Appendix). The only element of joint taxation in the 1998/99 fiscal year was the Married Couples Allowance (MCA). The MCA operated as a nonre fundable credit, ${ }^{2}$ and its maximum value in $1998 / 99$ was $£ 285$ (€410). Thus one person in a couple could reduce his/her tax bill by up to this amount, effectively extending the personal allowance by up to $£ 1,425$ ( $€ 2,070$ ) (and limiting the width of the $20 \%$ band). On top of income tax, individuals pay national insurance contributions. These are paid at $10 \%$ on the basis of gross weekly earnings from $£ 64$ (€93) per week up to an upper limit of $£ 485$ (€704) per week.

\footnotetext{
${ }^{1}$ Euro conversion rate: $£ 1 € 1.4524$ (based on www.ft.com currency converter, of April 17th, 2003).

${ }^{2}$ A non refundable credit reduces tax liability only if such a liability arises, i.e. only if an individual has enough income to pay income tax. This is different from a refundable credit, which can be paid out in a form of negative tax even in cases where an individual has no taxable income.
} 


\subsection{Means tested benefits}

The means tested benefit system in the UK is composed of four major elements. The most basic support is provided through Income Support and Job Seekers' Allowance (JSA). Low income households can also obtain rent rebates through Housing Benefit and reductions in council tax payments through Council Tax Benefit. Income Support is paid to poorest families conditional on special circumstances (such as certain types of disability or being a single parent). The unemployed, who do not qualify for Income Support, can receive the Job Seekers' Allowance, a benefit of the same value as Income Support but conditional on both a fortnightly confirmation of individuals' readiness to work, and a level of resources. For households whose net income exceeds $£ 15$ a week, and where none of the members works more than $16 \mathrm{~h}$ per week, for each $£ 1$ of extra net income, the amount of benefit paid through Income Support or Job Seeker's Allowance is reduced by $£ 1$. Housing Benefit and Council Tax Benefit can be claimed regardless of the number of hours worked, but when household net income exceeds the level of IS/JSA eligibility, for each $£ 1$ of extra net income the value of the benefits is reduced by $£ 0.65$. Income Support, Council Tax Benefit, Housing Benefit and noncontributory Job Seekers' Allowance are based on weekly income assessment and are not time limited.

\subsection{In work transfers}

Support through the Family Credit (FC) and its successor, the Working Families' Tax Credit (WFTC), is limited to families with dependent children. ${ }^{3}$ Payments are conditional on full time remunerative employment of at least one of the adults in the family, which is understood as no less than $16 \mathrm{~h}$ of work per week. Below we describe the Family Credit and then outline the main differences between FC and WFTC.

\subsubsection{Family credit}

Until October 1999, low paid working families with children (couples and individuals) can claim in work support in the form of Family Credit. In work support in the UK is con ditional on either of the adults in the family working at least $16 \mathrm{~h}$ per week and eligibility is based on net weekly family income and savings. The Family Credit comprises a "basic credit" plus credits for every child. The latter vary with the age of children. There is also a "full time" premium for families where either of the parents works $30 \mathrm{~h}$ per week or more. The maximum amount of in work support a family can receive depends on the number and ages of children. Whether it gets this family specific maximum or less depends on net family income. If net family income is at or below the "applicable amount" (whose value is the same for all families; in $1998 / 99$ it was equal to $£ 79.00$ per week) the family is entitled to its maximum amount of credit. If income exceeds the applicable amount, the family receives the maximum amount less a proportion of the difference between net income and the applicable amount. The proportion is equal to one minus the withdrawal rate (equal to $70 \%$ in 1998). The payments are based on a snapshot of family income at the time of application, usually the period of seven weeks before the application is made. The

\footnotetext{
${ }^{3}$ In April 2003, the WFTC was replaced by a new system of financial support for low income families with children. As part of the same package of reforms, the principle of in work support for the low paid has been extended to those without children in low paid full time employment. For details see Brewer (2003).
} 
transfer is then paid for a period of six months and the amount does not vary, regardless of changes in family circumstances (for details of values of the credit and other parameters of in work support, see Table A2 in the Appendix).

Unlike Income Support, Housing Benefit and Council Tax Benefit are not limited to $16 \mathrm{~h}$ of paid employment at low levels of income, so that families can claim these benefits and Family Credit together. This joint claim leads to very high marginal deduction rates, as the $70 \%$ withdrawal taper of Family Credit interacts with the tax system and the with drawal rates of the other means tested benefits. Figure 1 presents the budget constraint, which results from the interaction of the different elements of the UK tax and benefit system for a one earner family with one child. The family receives the universal Child Benefit, and depending on the number of hours worked, is eligible for various levels of means tested support. The figure shows that for a large range of hours of work, the effective marginal tax rate is close to $100 \%$ (and exceeds $100 \%$ at around $3234 \mathrm{~h}$ of work). This is a result of overlapping tax/National Insurance rates and withdrawal rates of means tested benefits. Obviously, the more means tested benefits an individual or family is eligible for, the more likely the problem of high marginal tax rates is going to be due to an overlap of withdrawal rates of benefits as income rises.

Budget constraints with high marginal tax rates over a long range of hours, similar to the one presented in Fig. 1, will be common among households with low levels of wages and high levels of eligibility. How much means tested and in work support households can receive is determined by three factors:

- the level of savings all means tested benefits and Family Credit are limited to households with low levels of savings ( $£ 8000$ for Income Support/JSA and Family Credit and $£ 16000$ for Housing Benefit and Council Tax Benefit),

- whether households live in owned or rented accommodation Housing Benefit is limited to those who pay rent,

- the number and ages of children in the household as the value of all elements of means tested support and the Family Credit are conditional on household structure.

Therefore households with children, living in rented accommodation, and with low level of savings are most likely to face very high marginal tax rates. Given the criterions for eligibility to the different schemes and the make up of the UK population in 1998, a large fraction of the labor force faces very high marginal tax rates over substantial ranges of hours worked. In 1998/99, there were about 33 million of working age adults in Britain. Of these, over 6 million were in receipt of some form of means tested support, which means that they faced a marginal tax rate of at least $65 \%{ }^{4}$ The 6 million benefit recipients is the lower bound of the number facing weak incentives to work. On top of the number of households who actually received support, there are those who were not entitled because of the level of their earned income but who would receive support at some lower level of hours worked. Taking the example of the budget constraint in Fig. 1, at $40 \mathrm{~h}$ of work the level of net earned income implies that the family would not be entitled to claim any means tested support. Yet, clearly the problem of weak work incentives still applies.

\footnotetext{
${ }^{4}$ In 1998, this was the lower withdrawal rate of means tested support (applied to Council Tax Benefit and Housing Benefit). For a detailed breakdown of the number of families on means tested benefits, see for example: Brewer, Clark, and Wakefield (2002), Department for Work and Pensions (2001).
} 


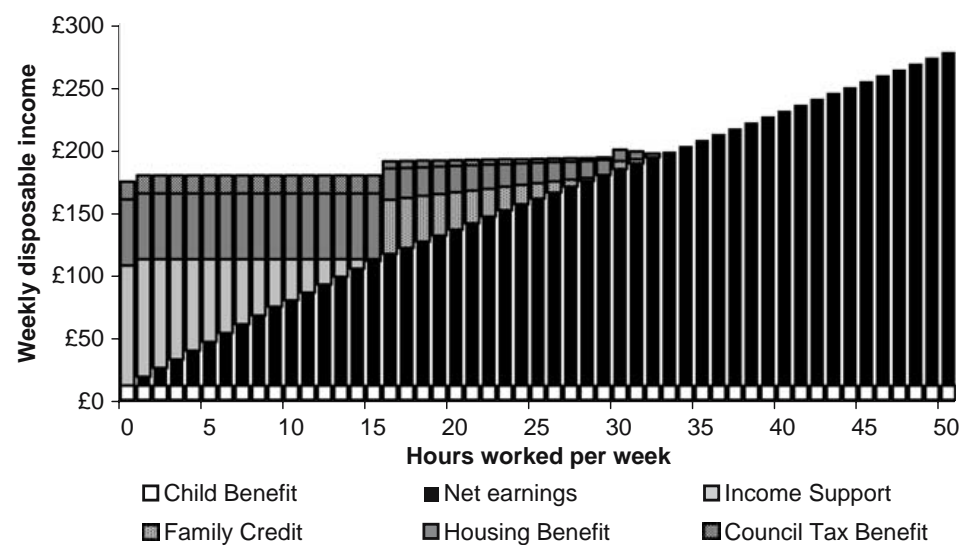

Fig. 1 The 1998/99 fiscal system one earner couple with a child aged under 11. Notes: Gross hourly wage of $£ 7.00$ ( $€ 10.17)$ the 25 th percentile wage for a man in couples with children; assumed rent is $£ 52.25$ $(€ 75.89)$ per week, the median rent for couples with children

\subsubsection{Working Families' Tax Credit}

In 1998, the Labour Government announced that the Family Credit would be replaced by the Working Families' Tax Credit. One of the issues the reform was to address was the problem of high marginal tax rates which resulted from the combination of income tax, national insurance contributions and the withdrawal of Family Credit, often combined with the withdrawal of the means tested Housing Benefit and Council Tax Benefit. The WFTC, introduced in October 1999, builds on the Family Credit (its structure, elements and operation are essentially the same) but it is substantially more generous.

The WFTC reform comprised increases of the applicable amount and specific credits. ${ }^{5}$ The withdrawal taper was reduced from 70 to 55 per cent. In addition, in an attempt to reduce the stigma associated with claiming in work support and thereby increase take up, as well as to strengthen the link between work and the transfer, it was originally planned that WFTC would be paid through the wage packet to the main earner rather than directly to the main carer as in the case of FC. This part of the reform raised concern over a "purse to wallet" transfer of money within couples and on its introduction couples have been left to choose whom the WFTC is paid to. ${ }^{6}$

Figure 2 shows the effect of WFTC (without childcare) compared with FC for a one earner family with one child at various hours of work. Although WFTC is a much more

\footnotetext{
5 In Table A2 in the Appendix, we present the difference in values of credits and applicable amounts between Family Credit in April 1998 and WFTC in June 2001. Values from June 2001 include several increases in the generosity of WFTC introduced after October 1999.

${ }^{6}$ WFTC includes also a generous childcare credit equivalent to 70 per cent of childcare costs up to a rather generous maximum. This is available to single parents and couples conditional on both partners working at least $16 \mathrm{~h}$ a week. The maximum amount of childcare credit is 70 per cent of childcare costs up to $£ 100$ for people with one child and up to $£ 150$ for those with two or more children. Under FC, there was an income disregard of $£ 60$ per week on childcare expenditure. Take up of child care related financial support has been low under both FC and WFTC and we do not include this part of the reform in our modeling. For details of how childcare support changed between Family Credit and WFTC see for example, Myck (2000).
} 


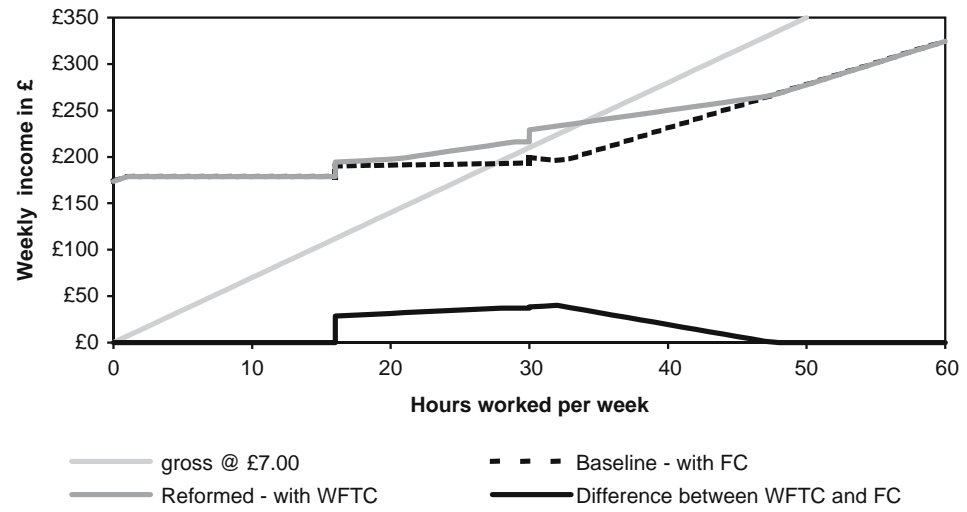

Fig. 2 Budget constraint for a one earner couple with child, for a gross hourly wage rate of $£ 7.00$, baseline (April 1998) and reform systems (Working Families' Tax Credit) Notes: See notes for Fig. 1. Net weekly income presented for two tax and benefit systems; gross weekly income presented for reference

generous system, a lot of the difference is clawed back through reduction in Housing Benefit and Council Tax Benefit. While WFTC increases net income at all hours of work/ earnings levels, it is interesting to note that the reform has had the highest impact (in absolute terms) on the net incomes of those who would be just at the end of the FC taper. Due to the WFTC's increased generosity and reduction in the taper rate, a lot of people who would not be eligible to claim FC because of their income level became entitled to claim WFTC. As a consequence the government expected a near doubling of the number of recipients of WFTC compared with FC. The reality of WFTC turned out not far off this expectation. While in November 1998 around 800000 families received the Family Credit, by November 2000, i.e. a year into the WFTC reform, the number of claimants had increased to just over 1.1 million and reached almost 1.4 million families by November 2002 (see Inland Revenue, 2002).

Since 1998/1999, apart from the WFTC, many other changes have been made to the structure of taxes and benefits in the United Kingdom. These have been described in detail elsewhere (for example: Adam \& Kaplan, 2002; Kaplan \& Leicester, 2002; Myck, 2000), and shall not be taken into account here.

\subsection{Modeling the WFTC reform}

The WFTC increased the generosity of in work transfers and changed the withdrawal taper of the transfer. Although, when eventually introduced it allowed couples to choose the person who would receive it, the initial proposal was to pay it in all cases to the main earner in each couple. This part of the reform would represent a significant shift of resources from main carers (in most cases mothers) who used to receive the Family Credit to main earners (in most cases fathers). Within the unitary framework, we would only be able to examine the effects of increased generosity of payments, but because the collective framework allows the analysis of the impact on choices of changes in the distribution of resources between partners, we will also be able to consider this aspect of the reform. 
We will analyze two hypothetical versions of the WFTC reform:

- WFTC1: increased generosity of the payments with no change of recipient (payments going to the main carer),

- WFTC2: increased generosity of payments with change of recipient from main carer to main earner.

\section{The data}

We use individual labor force data from the UK. We calibrate a collective model of household labor supply on couple data, in the way described by Vermeulen et al. (2006), and predict work hours according to the model. It is this predicted hours data (our "col lective" data) which we then use to simulate fiscal reforms. We first describe the UK labor force data, then report the results of two of the steps of the estimation and calibration exercise, namely the analysis of bargaining power inside couples and of the leisure interaction term in couples' preferences, as they are specific to the UK situation. We end this section with a description of the distribution of hours worked as predicted by the collective model.

\subsection{The UK labor supply data}

The data comes from the 1998/99 Family Resources Survey (FRS), which contains 22,999 households. The survey collects data on an individual basis on education, weekly hours of work, gross weekly earnings, investment income, as well as on a range of demographic characteristics. Other sources of income are recorded at the benefit unit (family) level. These are mainly government transfers: Income Support, Family Credit, Housing Benefit, sick and maternity pay, maintenance income, as well as the value of in kind benefits (e.g. free school meals). From weekly hours of work and gross earnings we calculate gross hourly wages. We use two sub samples of this data set:

- a sample of 1730 single individuals without children (922 men and 808 women) this sample is used to estimate singles' preferences,

- a sample of 4358 couples (1739 couples without children and 2619 couples with one or two children) this sample is used for estimation of labor supply models for couples and simulation of the WFTC reform.

The samples only include one benefit unit households and are limited to individuals aged 25 55. We exclude any individual or couple in which either of the partners is self employed, receives contributory Job Seekers' Allowance (the UK unemployment benefit), is retired or disabled, as we want to exclude households with individuals who are invol untarily out of work. We also excluded households with disabled children, and those with any adults in full time education and in the army. Households with more than two children, individuals with wages above $£ 50$ (€72.62) an hour and those with missing education information have also been excluded. ${ }^{7}$ Table A4 in the Appendix provides summary statistics.

\footnotetext{
${ }^{7}$ The WFTC reform only affects households with children. Our sample therefore includes households with children, where we limit the number of those to two, in an attempt to limit the potential effects of labor supply constraints which are not directly related to financial gains to work.
} 


\subsection{Estimation and calibration of a collective model}

To go from the data described above to the collective data used to study the impact of fiscal reforms, we take the following steps. Firstly, we estimate parameters of prefer ences for leisure and consumption on the sample of singles. ${ }^{8}$ We then turn to couples, whose preferences are assumed to be identical to those of singles, save for a term capturing the marginal utility of the leisure of each individual's partner. We assume that decisions of individuals in couples are Pareto efficient. We need to estimate the preference parameter on the leisure interaction term, together with the parameters of a function describing the bargaining power, or which point a household chooses on the Pareto frontier. We use both calibration and estimation to achieve this. As described in Vermeulen et al. (2006) in the first stage of calibration we obtain values of the man's welfare weight $\left(\mu_{\mathrm{m}}\right)$ and the parameter on the interaction of leisures in the individual utility functions of partners $(\delta) . \mu_{m}$ is defined as in Eq. (8) of Vermeulen et al. (2006):

$$
\mu_{m} \quad k_{*}\left(\delta_{*}\right) / K
$$

where $K$ is the number of discretized points between the man's maximum and minimum utility levels for an optimal $\delta=\delta *$, and $k_{*}$ is the optimal point between the two extremes. ${ }^{9}$

In the second stage we estimate a linear equation on the calibrated man's welfare weight and using predictions from this equation $\left(\hat{\mu}_{m}^{0}\right)$ recalibrate the $\delta .{ }^{10}$ For each household, we then predict the optimal consumption leisure choice, given the values of all parameters of the system. This data set of predicted optimal choices is the collective data set which we use to perform the fiscal reform simulations.

Before turning to the simulation of the reform we present the analysis of bargaining power and leisure interaction terms for the UK.

\subsubsection{Bargaining power}

We allow for bargaining power within households, as captured by the man's welfare weight $\mu_{m}$, to depend on relative wages (difference in gross wages between the man and the woman), relative investment income (difference in gross investment/savings income be tween the man and the woman), relative unearned income and on the earning potential implied by the tax and benefit system. From the point of view of the collective framework these variables (distribution factors) are crucial determinants of the distribution process. Bargaining power in our model also depends on the difference in age and education, and the number and ages of children (see, for example, Bourguignon, Browning, Chiappori, \& Lechene, 1993).

The relative earning potential implied by the tax and benefit system is defined as:

\footnotetext{
${ }^{8}$ For results of the estimation of the parameters of single individuals' utility functions see the Appendix (Table A3).

${ }^{9}$ We shall use interchangeably the terms "bargaining power"' and "welfare weight", in order simply to avoid tedious repetitions. But note that due to the nonconvexity of budget sets the welfare weight does not correspond to a linear combination of spouses' utilities.

${ }^{10}$ In this application of the Vermeulen et al. (2006) methodology we do not allow $\delta$ to be different for men and women, and we use calibrated rather than predicted values of $\delta$.
} 


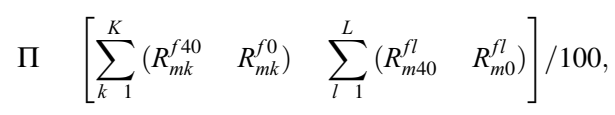

where $R_{m k}^{f l}$ is the total household income where the partners' labor supplies correspond to the $l$ th and $k$ th discretized hours bracket (respectively of the woman and the man). The hours distribution is discretized into $K$ and $L$ hour brackets. ${ }^{11}$ Earning potential is thus the difference between the man's and woman's contribution to the (net) household income, where the contribution is calculated as the sum of differences between incomes at 40 and $0 \mathrm{~h}$ of work of the partner over a number of hours brackets $K$ or $L$. If the tax and benefit system changes in such a way that it increases the man's contribution relative to the woman's, the value of the variable will increase. Such definition of the relative earning potential is a slightly simpler specification of the one suggested in Eq. (12) of Vermeulen et al. (2006), but its interpretation is essentially the same. The variable measures how much net income the female in the couple contributes to the household budget relative to the man's contribution, once we take account of the tax and benefit system and of the hours' options the partners can choose from.

From the formulation of the earnings potential variable presented above it should be obvious that it does not account for different forms of administration and payment of taxes and benefits. Yet precisely this aspect is central to analyzing the effects of the WFTC reform. Here we therefore include an additional variable which accounts for the distri bution of unearned income. The variable, which is an additional distribution factor, is defined as the relative woman's unearned income at $40 / 0 \mathrm{~h}$ worked, and takes the following form:

$$
Y_{f}^{\mathrm{UN}} \quad\left(F_{m 40}^{f 0} / R_{m 40}^{f 0}\right) * 100,
$$

$Y_{f} \mathrm{UN}$ is the ratio of woman's unearned income, $F_{m 40}^{f 0}$, to total couple's income, $R_{m 40}^{f 0}$, when the man is working $40 \mathrm{~h}$ and the woman is working $0 \mathrm{~h}^{12}$ This specific hours combination has been chosen given the rules determining in work support. At this com bination of hours most low income couples with children will still be eligible for FC and/or WFTC and the value of the variable should therefore change with changes in their gen erosity and administration. The variable, among other things, will allow us to capture the difference between the two versions of the WFTC.

Table 1 presents results of a simple (linear) regression of the male welfare weight, $w_{m}$, on the four distribution factors: $\Pi, Y_{f} \mathrm{UN}$, the difference between his and her gross wage, and the difference between his and her investment/savings income, and on a vector of other characteristics.

Living in London and having a child aged 04 negatively influences the male bar gaining position. Men who are better educated than their partners have less bargaining power than men who have either the same educational level or less, and the larger the difference in ages between the man and the woman, the lower the man's bargaining power. These last results go in the opposite direction of what has been found in most studies for other countries in this project. One of the possible explanations for these findings is the fact

\footnotetext{
${ }^{11}$ We split both the male and the female hours distributions into 7 h brackets: $05,615, \ldots, 4555,56+$, and calculate net incomes for these brackets respectively at: $0,10, \ldots, 50 \mathrm{~h}$ and $60 \mathrm{~h}$ of work. The value is divided by 100 for numerical and presentational reasons.

12 The scaling is again guided by the reasons given in Footnote 11. 
Table 1 Determinants of men's welfare weight a linear regression

\begin{tabular}{lcc}
\hline Dependent variable: Men's bargaining power: $\mu_{m}$ & Coefficient & SE \\
\hline Constant & $0.582^{* *}$ & $(0.005)$ \\
Difference in age & $0.002^{* *}$ & $(0.001)$ \\
Dummy variables for difference in education & & $(0.008)$ \\
$\quad$ Man's education 1 levels higher & 0.007 & $(0.015)$ \\
$\quad$ Man's education 2 levels higher & $0.039^{* *}$ & $(0.007)$ \\
$\quad$ Man's education 1 level lower & $0.024^{* *}$ & $(0.014)$ \\
$\quad$ Man's education 2 levels lower & $0.032^{* *}$ & $(0.006)$ \\
Youngest child aged 0 4 & $0.024^{* *}$ & $(0.007)$ \\
Youngest child aged 5 10 & $0.020^{* *}$ & $(0.002)$ \\
I UN & $0.014 * *$ & $(0.000)$ \\
$Y_{f}$ & $0.007^{* *}$ & $(0.004)$ \\
Difference in gross wage & $0.034^{* *}$ & $(0.009)$ \\
Difference in investment/savings income/100 & $0.027^{* *}$ & $(0.008)$ \\
Living in London & $0.043^{* *}$ & 4358 \\
Number of observations & 0.1915 &
\end{tabular}

Notes: Difference in age: his age minus her age. Dummy variables for education: level of education determined by the age when left full time education. Individuals are divided into three education groups: left school aged 16 or less, left school aged 17 or 18, and left school aged 19 or more. Dummy for 'Man's education 2 levels higher' takes value 1 if man left education aged 19+ and woman left education aged 16 or less. On the other hand, 'Man's education 1 level lower' take value one if either: woman left education aged 17 or 18 and man aged 16 or less, or if woman left education aged 19+ and man aged 1718 . The omitted education category is couples where both partners have the same level of education. The omitted youngest child category is youngest child aged 11 18. Difference in gross wage: his gross wage minus her gross wage. Difference in investment/savings income: his investment/savings income minus hers. (**) implies significance at $5 \%$

that, as mentioned by Vermeulen et al. (2006, Sections 3.1 and 3.2), our model ignores household production, and considers all nonlabor time as pure leisure. ${ }^{13}$ This implies that a situation in which the woman is not employed but the man is, or in which the woman works less than the man, is interpreted as a reflection of higher bargaining power of the woman (since she is treated as having more leisure). In many such situations women may in fact spend considerable amount of their nonlabor time on household work and childcare, and this would presumably be more likely in couples where the man is better educated and older (and thus relatively more 'productive' on the labor market). It is therefore possible these counterintuitive effects could disappear if we treated household production explicitly in the model. Our finding thus stresses the importance of extending the model to include household production. On top of this one could also argue that because the socio demographic characteristics determine both the bargaining power and either preferences or the budget constraint (or both) there is no obvious a priori expectation concerning the direction in which they would affect the bargaining position in the household. ${ }^{14}$

The coefficients on the distribution factors, except for the coefficient on the difference between his and her investment income, have the expected signs. Higher gross wage of the man relative to the gross wage of his partner, higher earning potential ( $\Pi$ ) and lower values of female unearned income $\left(Y_{f} \mathrm{UN}\right)$ all imply a higher bargaining power of the man. In Table 2 we present summary statistics for the calibrated and estimated values of the parameters of the collective model: men's welfare weight, $\mu_{\mathrm{m}}$, and the coefficient on the

\footnotetext{
${ }^{13}$ See Vermeulen et al. (2006) for some qualification of this statement.

${ }^{14}$ See Section 6 for results obtained for other countries.
} 
Table 2 Summary statistics for calibrated and estimated parameters of the collective model

\begin{tabular}{lllll}
\hline & Mean & Standard deviation & Min. value & Max. value \\
\hline Calibrated $\mu_{m}$ & 0.565 & 0.181 & 0 & 1 \\
Estimated $\mu_{m}$ & 0.565 & 0.080 & 0.094 & 0.973 \\
Calibrated $\delta$ & 0.066 & 0.361 & 0.9 & 4.0 \\
\hline
\end{tabular}

Table 3 Hours distributions: actual and collective predictions

\begin{tabular}{llllll}
\hline & \multicolumn{2}{l}{ Men } & & \multicolumn{2}{l}{ Women } \\
\cline { 2 - 3 } \cline { 5 - 5 } & Actual (\%) & Predicted (\%) & & Actual (\%) & Predicted (\%) \\
\hline Hours bracket & & & & 14.4 \\
From 0 to 5 & 3.1 & 1.9 & 16.4 & 12.8 \\
From 6 to 15 & 0.2 & 0.3 & 7.1 & 19.7 \\
From 16 to 25 & 0.7 & 1.4 & 17.9 & 19.5 \\
From 26 to 35 & 1.4 & 2.6 & 3.9 & 23.2 \\
From 36 to 45 & 44.3 & 27.6 & 8.9 & 8.4 \\
From 46 to 55 & 32.2 & 53.2 & 2.7 & 2.3 \\
Above 56 & 18.3 & 13.2 & & 13.9 \\
\hline
\end{tabular}

interaction of leisure terms in the utility function, $\delta$. Relative to the calibrated value of $\mu_{\mathrm{m}}$ there is much less variation in the estimated parameter.

\subsection{The collective data set}

Each observation in the collective data set corresponds to a household for which the hours of work of the two adult members have been predicted using the collective model (with estimated bargaining power and leisure interaction terms). Household income is also predicted given wages, unearned income and predicted hours of work. To assess the quality of our prediction, we compare the distributions of hours in the data and as predicted by the model.

We find that predicted hours and actual hours coincide for $51.0 \%$ of men and $56.1 \%$ of women, and that for a further $41.4 \%$ of men and $36.4 \%$ of women, the prediction is within $1 \mathrm{~h}$ bracket of the actual number of hours worked. Table 3 shows the percentage of observations in each of $7 \mathrm{~h}$ brackets, for numbers of hours worked, both actual and as predicted by the collective model. Overall, the model's predictions are not far off from the actual distribution of hours worked. For both men and women the model underpredicts the proportion working between 36 and $45 \mathrm{~h}$ per week, which is the most common observed combination of hours worked.

\section{Theoretical effects of a reform of the tax and benefit system}

We discuss the theoretical effect of a reform such as that of in work transfers implemented in the UK in 1999, both in the unitary and the collective frameworks. 
As we mentioned above, the 1999 WFTC reform has two important aspects. Firstly, it represents an increase in generosity of in work support for families with children, and secondly it introduces an option of payments via the pay packet. ${ }^{15}$

The first element of the reform increase in the value of in work benefit expands the opportunity set for those couples with children who at some combination of hours worked would potentially be eligible to claim WFTC. Because of conditions restricting eligibility for in work support, some couples with children will not see a change in their budget constraint. Increased generosity of the payments will not affect: ${ }^{16}$

- households with levels of savings which make them ineligible to claim WFTC, ${ }^{17}$

- households where wages of both partners are so high that even at the minimum required level of hours the couple is not eligible to claim any WFTC.

The second element of the reform, the option of payment via the pay packet, is not innocuous. Indeed, to the change in payment mode can be associated a change in identity of recipient within the household, and this in turn may lead to behavioral changes for a given level of the transfer.

\subsection{Effect of the WFTC reform in the unitary framework}

Since the unitary model implies that household resources are pooled, in such a framework the amount of a transfer but not the identity of the transfer recipient influences household choices. Therefore, in a unitary framework, whether the WFTC is paid to the mother or to the main earner will have no effect on behavior, and thus households will respond in the same way to both variants of the reform we consider, which both amount to an increase of non labor income. If leisure of both household members is normal, labor supply should decrease, and the extent of the decrease will depend on the relative marginal utility of leisure and of other goods in the household preferences. We can expect larger effects if individual wages are very different, with the low wage partner more likely to leave work. Finally, because receipt of the WFTC is conditional on at least one person working $16 \mathrm{~h}$, we should not see any couple with at least one person in work prior to the reform become a 'workless' family.

An important feature of the unitary model is the fact that potentially higher incomes in 'sub optimal' scenarios have no effect on the final decision. This means that any change in labor supply will take place only among those who following the reform actually end up claiming the WFTC. In other words, if in the baseline and reform systems the highest level of utility is achieved at a point where the household is not eligible to claim any FC/WFTC, then the fact that they could claim it at some different level of hours worked will not affect their behavior. In the unitary framework, if couples change their behavior following the reform, the new optimum has to be at a point where they receive some WFTC. As we shall see below, this is not necessarily the case in the collective model.

\footnotetext{
${ }^{15}$ Note that the WFTC retains the conditionality of the transfer on a minimum number of hours worked (16 h per week worked by either member) as in its predecessor, the Family Credit.

${ }^{16}$ Out of 2619 couples with children in our sample, the budget constraint is unchanged by the WFTC for 676 couples.

${ }^{17}$ WFTC is restricted to those with savings less than $£ 8000$. Eligibility is reduced (by $£ 1$ for every $£ 250$ of savings) for those with savings above $£ 3000$.
} 


\subsection{Effect of the WFTC reform in the collective framework}

Households behaving collectively will be affected by a broader set of reforms than unitary households. Indeed, collective households will not only react to reforms which change total income, but also, potentially at least, to reforms which modify any of the arguments of the intra household bargaining power. Typically, bargaining power depends on relative wages or relative earning potential. For the UK, recall that we found bargaining power to depend significantly on differences in gross hourly wages and investment income, unearned in come of the woman relative to overall income at the 400 (his her) combination of hours worked, and on the earning potential implied by the tax and benefit system.

From the perspective of mechanisms through which relative earning potential and distribution of resources influence behavior in couples in the collective model we can distinguish three types of tax and benefit reforms:

1) Reforms which only affect the distribution of resources but not their overall level: an example of this is a hypothetical reform of the Child Benefit, with change in the identity of the recipient and constant amount of benefit. Such a reform affects neither the Pareto frontier nor the contributions to the household's income (captured in our setting by the $\Pi$ variable). In our model, the only way such a reform affects the distribution of resources within the family is via the ratio of unearned income of the woman to the total household income (i.e. $Y_{f} \mathrm{UN}$ variable).

2) Reforms which affect both the Pareto frontier and the distribution of resources within households. In the light of our model, we can distinguish two types of such reforms:

a. reforms which do not affect the distribution of unearned income (as summarized in the $Y_{f} \mathrm{UN}$ variable), ${ }^{18}$

b. reforms which change both the relative contributions to the household's income (П) and have an effect on the distribution of unearned income $\left(Y_{f}^{\mathrm{UN}}\right)$.

Most fiscal reforms, including the WFTC reform, fall into the last category. For households who would be potentially eligible for the WFTC, the reform changes the shape of the Pareto frontier, as well as the relative contribution to the household budget $\Pi$, and for many couples with children, it affects the level of the female unearned income to total household income. Because of the last effect we expect to see a difference in the response to the reform depending whether in work support is paid to the main carer or the main earner.

Unlike in the unitary framework, where the reform affects household behavior only through changes in the family budget constraint, response to the WFTC in the collective framework will be a combination of two effects: responses to changes in the Pareto frontier and to changes in the relative bargaining power resulting from different values of $\Pi$ and $Y_{f} \mathrm{UN}$. The implication of the change in the bargaining power is that in the collective framework, we might observe changes in behavior of couples who neither before nor after the reform claim any in work support. We analyze below what the likely effects of the reform are in terms of labor supply decisions and how the reform will influence the relative bargaining power of the partners.

\footnotetext{
${ }^{18}$ It is difficult to think of an example of such a reform in the case where we define the distribution of unearned income relative to overall net family income. Any reform affecting net incomes would change the value of the variable summarizing this distribution even if absolute values of unearned incomes remained unaffected.
} 


\subsubsection{Changes in bargaining power}

Two of the distribution factors we consider which could be affected by the WFTC reform are the earning potential variable, $\Pi$, and the ratio of unearned income of the woman to total household income at the $400 \mathrm{~h}$ combination, $Y_{f} \mathrm{UN}$.

4.2.1.1. WFTC and the earning potential variable. Because the $\Pi$ variable measures the contributions to the overall household income and disregards the way income is distributed between partners, its value will be the same regardless of who receives the WFTC. The WFTC reform will affect the value of $\Pi$, since the reform changes the household budget constraint, but the value after the reform will be the same for WFTC1 and WFTC2. Since the reform potentially increases the contribution of each partner to the household income, the earning potential variable can either increase or decrease, depending on which contribution increases most. It is therefore ambiguous how the bargaining power of the partners will change as a result of increasing the generosity of in work support.

Consider the effect of the WFTC reform on the earning potential variable $\Pi$. The reform increases the amount of in work support which the couple receives at combinations of hours worked at which their level of income makes them eligible for it. For the moment, it is not relevant who receives the payments, since we are concerned with contributions of each of the partners to the overall household income.

The increased generosity of payments will affect the difference in the household income between working and not working given the labor supply of the partner, i.e. for the man the value of: $R_{m 40}^{f l} \quad R_{m 0}^{f l}$ and the woman the value of: $R_{m k}^{f 40} \quad R_{m k}^{f 0}$ (see above). Focusing on $R_{m 40}^{f l} \quad R_{m 0}^{f l}$ it is unclear whether this difference will be positive or negative. Because WFTC is means tested, we would expect the reform to increase $R_{m 0}^{f l}$ (if $f l>16$ to make the family eligible for the WFTC) by more than it increases $R_{m 40}^{f l}$. However, Fig. 2 shows that this does not have to be the case: the highest increase in household income occurs at a relatively high level of hours worked. This will be the case especially if the man's wages are low enough to make the couple eligible for WFTC in the scenario when he works $40 \mathrm{~h}$. The difference: $R_{m 40}^{f l} \quad R_{m 0}^{f l}$ will therefore be likely to increase (thus reducing the value of the $\Pi$ variable) for couples where the man's wage is low. Similarly $R_{m 40}^{f l} \quad R_{m 0}^{f l}$ will be likely to increase for couples where the woman's wage is low.

Given the complex nature of the in work support system and the complexity of the $\Pi$ variable itself, it is difficult to give more satisfactory intuition as to how the earning potential variable should change with the introduction of the reform. It is important to remember, though, that increased generosity of in work support does not have to imply higher bargaining power of either the man or the woman.

\subsubsection{WFTC and the expected ratio of unearned income of the woman to total household} income. The value of the $Y_{f} \mathrm{UN}$ variable will change as a result of the increased gen erosity of in work support and it will differ depending on the recipient of WFTC payments. It will be lower when the transfer is paid to the father rather than to the mother. Since the WFTC2 reform gives the payment to the main earner (and in the 400 combination of hours it will be the father), and WFTC1 always gives it to the mother, the value of $Y_{f}^{U N}$ will be lower with WFTC2 than with WFTC1 for all couples eligible for in work support at the 400 combination of hours. This intuitive result is corroborated by the negative sign of the coefficient on the $Y_{f}^{U N}$ variable in the estimation of the bargaining power equation 
(Table 1). The comparison between men's bargaining power under WFTC1 and WFTC2 is unambiguous: men's bargaining power is greater under the option where they receive a higher level of transfer (WFTC2) than under the option where they do not (WFTC1).

This does not mean however that following the WFTC2 the bargaining power of the man will be higher than under the base tax and benefit system with Family Credit. The positive effect on the man's bargaining power of changing the recipient of in work support can still be outweighed by a possible negative effect of the reform on the earning potential variable П. It is therefore difficult to give a clear cut prediction of the effect of the introduction of the WFTC (in either of its variants) on the bargaining position of house holds.

\subsubsection{Changes in households' labor supply}

The outcome of the reform in terms of labor supply decisions of individuals in couples is less obvious in the collective framework than it is in the unitary model. Let us consider the potential effect of an increase in the bargaining power of the man as a result of changing the distribution of resources between partners, for a given level of transfer. In the framework of our model, this would have a straightforward positive effect on the bar gaining power of the man in all couples with children, without changing the highest $\left(U_{\max }^{m}\right)$ and lowest $\left(U_{\min }^{m}\right)$ levels of utility he can achieve. Our model then allows the woman in each couple to find the highest level of her utility conditional on the utility of her partner satisfying the condition:

$$
U^{m}\left(c_{m}, l_{m}, l_{f}\right) \geq U_{\min }^{m}+\hat{\mu}_{m}^{R}\left(U_{\max }^{m} \quad U_{\min }^{m}\right),
$$

where $\hat{\mu}_{m}^{R}$ is the predicted value of the man's welfare weight in the reformed system. To find the optimal solution, we do a double grid search on both hours and share of con sumption of the woman. At each of the 49 possible hours choices, and for each value of the share of consumption between 0.1 and 0.9 , we calculate the woman's utility.

Therefore, depending on preferences concerning the leisure consumption trade off, an increase in bargaining power of the man might imply a reduction in male labor supply, an increase in the share of consumption of the man, or both. This could be (but does not have to be) accompanied by an increase of female labor supply, a reduction in female share of consumption, or both. Women with higher preference for leisure would be more likely to respond by reducing their share of consumption, while those with higher preference for consumption would be more likely to increase their labor supply.

The issue is complicated further by the fact that each individual's utility is directly affected by the level of his or her partner's leisure. This implies that for example, if the coefficient on interaction of leisure terms in the partners' utility functions $\delta$ is positive, then an increase in his level of utility (to reflect his higher bargaining power) might be achieved even in a situation when his leisure and consumption fall, provided her leisure increases to compensate. On the other hand, if $\delta$ is negative then higher utility of the man can be achieved even in a situation when his consumption falls and his leisure remains unchanged, provided that her leisure falls enough.

The above example shows that even in the case of a simple reform where we only transfer resources between partners, it is unclear how we would expect couples to respond in terms of changes in individual labor supply and consumption. Matters get even more complicated once, apart from the change in bargaining power, a reform leads to a shift in the Pareto frontier, as is the case with the increased generosity of payment in the WFTC 
reform. Predicting how couples would respond to the introduction of WFTC is in our framework extremely difficult and it seems that the framework allows the reform to lead to outcomes which may seem rather unintuitive.

\section{Effect of the WFTC reform in the collective model}

We simulate the WFTC reform under the assumption that households behave as described by the collective model which has been used to generate the data.

Below we report the results of simulations of the WFTC reform in its two forms: WFTC1 reform where the more generous benefits are paid to the main carer, and WFTC2 where the more generous benefits are paid to the main earner. We discuss changes in the man's predicted bargaining power and changes in hours choices after the reform. We also present a brief welfare analysis.

\subsection{Effect of the reforms on the man's bargaining power}

As discussed in Section 4.2, the theoretical effect of the reforms on men's bargaining power is ambiguous. We expect the man's bargaining power to be greater in WFTC2 than in WFTC1, but recall that for some households it could decrease with both reforms.

Figures 3 and 4 show that the two versions of the reform have very different effects on the bargaining power of men, as is expected, given that men's resources are different in both variants. In both figures, we represent the man's welfare weight after the reform $\left(\hat{\mu}_{m}^{R 1}\right.$ and $\left.\hat{\mu}_{m}^{R 2}\right)$ as a function of the welfare weight before the reform $\left(\hat{\mu}_{m}^{0}\right)$. The line across each figure is the $45^{\circ}$ line. The difference between these two figures is a sole result of the effect of the redistribution of resources from the woman to the man, which is captured by the change in the $Y_{f} \mathrm{UN}$ variable. Indeed, as discussed above, changes in the earning potential variable $\Pi$ (and its effect on bargaining power) are the same regardless of who receives the payments.

Among the 2619 couples with children, relative to the pre reform level, bargaining power changes in 1946 cases, and out of those, in 1163 couples, men's bargaining power under WFTC1 is lower than men's bargaining power under WFTC2. Bargaining power does not change as a result of the reform only for 673 couples with children. In all these cases this is because the variables which summarize the effect of the tax and benefit system on bargaining power are unaffected by the reform. For a large majority of these couples, the reason is that WFTC is restricted because of high level of savings (over $£ 8,000$ $(€ 11,620))$, which makes them ineligible to claim in work support.

The first version of the reform, in which the amount of the transfer is increased with no change in the identity of the recipient (the main carer, i.e. by default the woman), increases the bargaining power of the woman in 1174 couples and lowers it in 772 couples. It is interesting to note a clear pattern which emerges from Fig. 3. In couples where the bar gaining power of the man is highest before the reform, the WFTC reform has very little effect. Bargaining power changes most for couples with the men's original welfare weight at about 0.5 and below this level.

Giving the WFTC to the main earner (in our simulation always the father) results in an increase of the bargaining power of men in 1741 couples. In 205 cases the man's bar gaining power is lower as a result of the reform. This happens because the earning potential variable $\Pi$ changes in favor of women, which in some cases is enough to outweigh the 


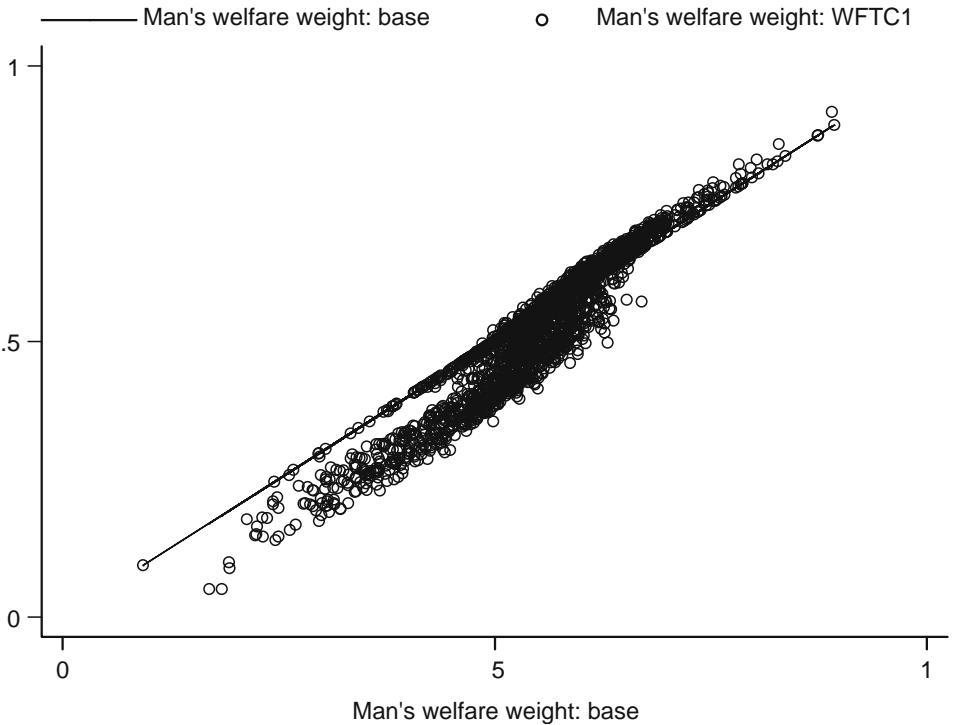

Fig. 3 The man's welfare weight before and after the WFTC1 reform in couples with children Notes: Man's post reform welfare weight $\left(\hat{\mu}_{m}^{R 1}\right)$ on the vertical axis

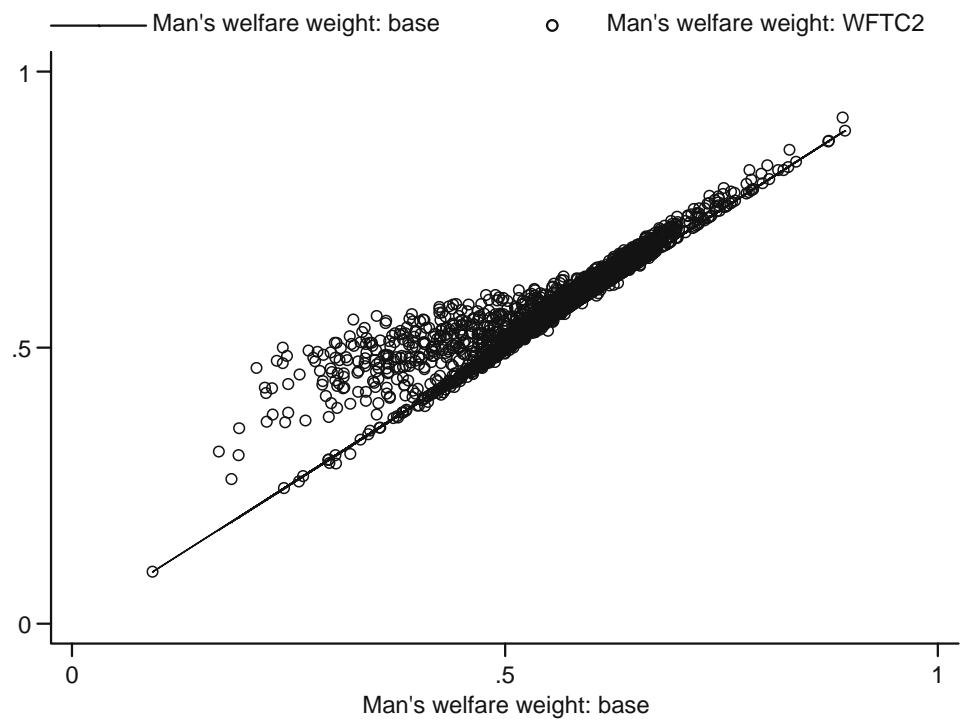

Fig. 4 The man's welfare weight before and after the WFTC2 reform in couples with children Notes: Man's post reform welfare weight $\left(\hat{\mu}_{m}^{R 2}\right)$ on the vertical axis 
effect of redistribution of payments from " purse to wallet', As we can see from Fig. 4 the loss of bargaining power by men in these situations is minimal.

\subsection{WFTC1 and WFTC2: changes in participation and hours}

We present the results we obtain in terms of hours and participation with both reforms, and compare the effects of WFTC1 and WFTC2. Tables 4 and 5 present changes in hours worked for men and women in couples with children as a result of, respectively, WFTC1 and WFTC2. In about $50 \%$ of couples, at least one household member changes his/her labor supply following the introduction of either of the WFTC reforms. Given the fact that we model the reform in a world with discretized and not continuous hours choices this is a surprisingly high proportion. ${ }^{19}$ We must remember, though, that unlike in the unitary model, the collective framework can lead to a behavioral change even though the couple receives no in work support before or after the reform. In fact, out of 1342 couples in which labor supply of either or both partners changes following WFTC1 reform, only $34.5 \%$ are eligible to claim in work support given their post reform labor supplies (the respective numbers for WFTC2 are 1253 and 40.5\%). The reason for this is the effect of the reform on the earning potential variable and the distribution of unearned income. These changes result in different relative bargaining power irrespective of whether the couple in the end receives the WFTC or not. Such an effect is unique to the collective model, and cannot be captured by simulations of the reforms using the unitary specification.

Table 4 WFTC1, changes in male and female hours couples with children

\begin{tabular}{lllllll}
\hline Change in male hours & \multicolumn{6}{l}{ Change in female hours } \\
\cline { 2 - 6 } & $\leq 20$ & 10 & 0 & 10 & $\geq 20$ & Total \\
\hline$\leq 20$ & $2.3 \%$ & $1.9 \%$ & $1.2 \%$ & $0.0 \%$ & $0.0 \%$ & $5.4 \%$ \\
10 & $2.9 \%$ & $4.7 \%$ & $4.2 \%$ & $1.2 \%$ & $0.0 \%$ & $12.9 \%$ \\
0 & $1.3 \%$ & $6.5 \%$ & $48.8 \%$ & $7.0 \%$ & $0.4 \%$ & $63.9 \%$ \\
10 & $0.4 \%$ & $3.9 \%$ & $9.3 \%$ & $1.4 \%$ & $0.2 \%$ & $15.1 \%$ \\
$\geq 20$ & $0.1 \%$ & $0.4 \%$ & $2.1 \%$ & $0.1 \%$ & $0.0 \%$ & $2.7 \%$ \\
Total & $7.0 \%$ & $17.3 \%$ & $65.4 \%$ & $9.6 \%$ & $0.6 \%$ & 2619 couples \\
\hline
\end{tabular}

Table 5 WFTC2, changes in male and female hours couples with children

\begin{tabular}{lllllll}
\hline Change in male hours & \multicolumn{6}{l}{ Change in female hours } \\
\cline { 2 - 7 } & $\leq 20$ & 10 & 0 & 10 & $\geq 20$ & Total \\
\hline$\leq 20$ & $2.3 \%$ & $4.4 \%$ & $3.1 \%$ & $0.3 \%$ & $0.1 \%$ & $10.1 \%$ \\
10 & $1.1 \%$ & $5.7 \%$ & $4.9 \%$ & $2.1 \%$ & $0.1 \%$ & $14.0 \%$ \\
0 & $0.6 \%$ & $3.4 \%$ & $52.2 \%$ & $8.5 \%$ & $0.4 \%$ & $65.0 \%$ \\
10 & $0.2 \%$ & $0.7 \%$ & $7.1 \%$ & $1.0 \%$ & $0.4 \%$ & $9.2 \%$ \\
$\geq 20$ & $0.0 \%$ & $0.0 \%$ & $1.6 \%$ & $0.0 \%$ & $0.0 \%$ & $1.7 \%$ \\
Total & $4.0 \%$ & $14.2 \%$ & $68.9 \%$ & $11.8 \%$ & $1.0 \%$ & 2619 couples \\
\hline
\end{tabular}

\footnotetext{
${ }^{19}$ If we simulated the reform in a framework which would allow modeling the choice of labor supply with a continuous hours distribution we would expect a change in the labor supply of all couples who would see their Pareto frontier and/or bargaining power change as a result of the WFTC.
} 
The proportion of men in couples with children who do not change their labor supply following the reform is slightly lower than the proportion of women who do not change their labor supply, both under WFTC1 and WFTC2. As we expected, relative to the response to WFTC1, under WFTC2 fewer women reduce their labor supply and more women respond by increasing their hours of work. This comes from the fact that both income and bargaining power of the woman are lower under WFTC2 than under WFTC1. The converse is true for men. The proportion of men reducing their hours following WFTC1 is almost 6 percentage points lower than following WFTC2.

Tables 6 and 7 give a summary of differences in labor supply between the two versions of WFTC for men and for women, respectively. Although, Tables 4 and 5 suggest a relatively high degree of similarity in the reaction to the two versions of the WFTC, looking at how men and women respond shows a striking disparity between the results. For $24 \%$ of men and $19 \%$ of women in couples with children the reforms have a different effect on behavior on the labor market. Given that $56 \%$ of men and $60 \%$ of women with children do not respond to either of the reforms, this means that around a half of those who do respond reacts differently depending on whether the WFTC is paid to the main carer or the main earner.

\subsection{Participation, consumption and welfare}

In Table 8, we present an aggregate summary of the results in terms of participation, consumption and welfare. The second column shows information for the collective data, while the third and fourth shows aggregate values for the two WFTC simulations in the collective world. We can see that both versions of the reform have a positive effect on male participation. When male bargaining power increases as a result of giving the WFTC to the

Table 6 WFTC1 vs. WFTC2, changes in male hours

\begin{tabular}{lllllll}
\hline Change in male hours WFTC1 & \multicolumn{6}{l}{ Change in male hours WFTC2 } \\
\cline { 2 - 6 } & $\leq 20$ & 10 & 0 & 10 & $\geq 20$ & Total \\
\hline$\leq 20$ & $3.8 \%$ & $1.3 \%$ & $0.3 \%$ & $0.0 \%$ & $0.0 \%$ & $5.6 \%$ \\
10 & $3.7 \%$ & $7.0 \%$ & $2.1 \%$ & $0.1 \%$ & $0.0 \%$ & $12.9 \%$ \\
0 & $2.1 \%$ & $4.7 \%$ & $56.1 \%$ & $1.1 \%$ & $0.0 \%$ & $63.9 \%$ \\
10 & $0.5 \%$ & $1.0 \%$ & $6.0 \%$ & $7.5 \%$ & $0.2 \%$ & $15.1 \%$ \\
$\geq 20$ & $0.0 \%$ & $0.1 \%$ & $0.6 \%$ & $0.5 \%$ & $1.5 \%$ & $2.7 \%$ \\
Total & $10.1 \%$ & $14.0 \%$ & $65.0 \%$ & $9.2 \%$ & $1.7 \%$ & 2619 couples \\
\hline
\end{tabular}

Table 7 WFTC1 vs. WFTC2, changes in female hours

\begin{tabular}{lllllll}
\hline $\begin{array}{l}\text { Change in female } \\
\text { hours WFTC1 }\end{array}$ & \multicolumn{6}{l}{ Change in female hours WFTC2 } \\
\cline { 2 - 6 } & $\leq 20$ & 10 & 0 & 10 & $\geq 20$ & Total \\
\hline$\leq 20$ & $3.0 \%$ & $2.4 \%$ & $1.5 \%$ & $0.1 \%$ & $0.0 \%$ & $7.0 \%$ \\
10 & $0.8 \%$ & $9.7 \%$ & $6.2 \%$ & $0.5 \%$ & $0.0 \%$ & $17.3 \%$ \\
0 & $0.2 \%$ & $1.8 \%$ & $59.6 \%$ & $3.5 \%$ & $0.3 \%$ & $65.4 \%$ \\
10 & $0.0 \%$ & $0.2 \%$ & $1.6 \%$ & $7.6 \%$ & $0.2 \%$ & $9.6 \%$ \\
$\geq 20$ & $0.0 \%$ & $0.0 \%$ & $0.0 \%$ & $0.1 \%$ & $0.5 \%$ & $0.6 \%$ \\
Total & $4.1 \%$ & $14.2 \%$ & $68.9 \%$ & $11.8 \%$ & $1.0 \%$ & 2619 couples \\
\hline
\end{tabular}


Table 8 WFTC reforms couples with children

\begin{tabular}{llll}
\hline & Collective data & WFTC1 & WFTC2 \\
\hline Participation & & & $98.7 \%$ \\
$\quad$ Men & $97.8 \%$ & $99.1 \%$ & $75.5 \%$ \\
$\quad$ Women & $81.1 \%$ & $73.7 \%$ & 44.6 \\
Hours of work & & & 27.8 \\
$\quad$ Men & 47.5 & 46.6 & $1.2 \%$ \\
$\quad$ Women & 26.9 & 26.7 & $0.1 \%$ \\
Proportion of families & & & $23.4 \%$ \\
$\quad$ No one in work & $2.2 \%$ & $0.9 \%$ & $75.4 \%$ \\
$\quad$ Only woman in work & $0.1 \%$ & $0.0 \%$ & 242.9 \\
$\quad$ Only man in work & $16.7 \%$ & $25.4 \%$ & $73.7 \%$ \\
$\quad$ Both in work & $81.1 \%$ & & 292.1 \\
Consumption & & 233.9 & 38.0 \\
$\quad$ Men & 239.0 & 303.1 & 47.8 \\
$\quad$ Women & 299.9 & 37.5 & 48.3 \\
Utility & & & \\
$\quad$ Men & 37.8 & & \\
$\quad$ Women & 48.0 & & \\
\hline
\end{tabular}

Table 9 Individual level welfare analysis of the WFTC reform

\begin{tabular}{|c|c|c|c|c|c|c|c|}
\hline \multicolumn{4}{|l|}{ WFTC1 } & \multicolumn{4}{|l|}{ WFTC2 } \\
\hline \multirow[t]{2}{*}{ Change in Um } & \multicolumn{3}{|c|}{ Change in Uw } & \multirow[t]{2}{*}{ Change in Um } & \multicolumn{3}{|c|}{ Change in Uw } \\
\hline & & 0 & + & & & 0 & + \\
\hline & 0.0 & 0.0 & 37.3 & & 0.0 & 0.0 & 2.8 \\
\hline 0 & 0.0 & 42.5 & 0.0 & 0 & 0.0 & 49.7 & 0.0 \\
\hline+ & 16.8 & 0.0 & 3.3 & + & 37.4 & 0.0 & 10.1 \\
\hline
\end{tabular}

Notes: Figures in percentages of couples with children. Um man's utility, Uw woman's utility

main earner, the effect on male participation is lower than when WFTC is paid to the main carer (men have more bargaining power, hence increase participation less). The reverse is true for women. The changes in participation following the reforms imply that under WFTC2 there is a higher number of workless couples. On average male consumption falls under WFTC1 and female consumption falls under WFTC2.

An important advantage of the collective model is the possibility to analyze changes in the individual levels of utility. As Table 8 shows on average utility of women increases under WFTC1 and falls under WFTC2 and the reverse is true for average utility level of men. ${ }^{20}$ However, neither of the versions of the reform unambiguously increases the utility of all men or all women. Because of the effect of increased generosity of payments between Family Credit and WFTC, and the resulting changes in bargaining power, both variants of the reform have positive and negative effect on utility of men and women.

In Table 9, we present a summary of changes in utility levels. About $42.5 \%$ of couples with children are not affected by the WFTC1 reform and at all. This proportion is higher (at $49.7 \%$ ) in the case of WFTC2. This may be because the couples are not eligible to claim

\footnotetext{
${ }^{20}$ Note that the interpretation of aggregate changes in utility requires some caution as averaging across individuals and households implies cardinalization of utility. However, we use these average figures only to reflect differences between the three systems and we think that these reflect the implications of the two versions of WFTC.
} 
any WFTC or because changes in the budget constraint and/or bargaining power are so small that the individual levels of leisure and consumption are unaffected in our discretized approach. WFTC1 positively affects utility of both men and women in only $3.3 \%$ of couples with children, WFTC2 in $10.1 \%$. Differences between the two variants of the reform come out especially when we look at the proportions of couples where one partner gains and the other looses. Following WFCT2 the proportion of couples where the man gains and the woman loses is $37.4 \%$ which is almost double the figure under WFTC1. On the other hand, if the more generous payments are given to the mother, in $37.3 \%$ of couples with children the woman's utility level increases and the utility of her partner falls. ${ }^{21}$

\section{Summary of comparable results for five other European countries}

Similar analysis was conducted for reforms of the tax and benefit systems in Belgium, France, Germany, Italy, and Spain. ${ }^{22}$ The papers use the same or very similar methodology (described in Vermeulen et al., 2006), but are applied to different reforms and based on country specific data. Below we present a summary of results from these studies. In the description of these results we focus on the determinants of the relative bargaining power, the nature of modeled reforms and on some key effects they bring about. As far as determinants of bargaining power are concerned, the signs of the estimated coefficients are given in parentheses.

\subsection{Belgium}

The distribution of the woman's estimated power index has a mean of .62, but is very asymmetric, as it is approximately unimodal with mode near .94. Significant determinants are her expected marginal contribution to household disposable income when switching from 0 to $40 \mathrm{~h}$ worked per week (+), his corresponding expected increment when switching from 30 to $40 \mathrm{~h} \mathrm{(-),} \mathrm{her} \mathrm{minus} \mathrm{his} \mathrm{unearned} \mathrm{income}(+)$, total household unearned income $(+)$, living in Brussels (-), higher education indicators (both his and her - ) and white collar indicators (his + , her - ). Note that the variables with a direct "collective" interpretation have the expected sign.

The reform currently implemented (henceforth "Belgian reform") consists of four main measures: (i) introduction of a repayable tax credit for low earnings; (ii) changes in tax brackets and lowering of the two highest marginal tax rates from 55\% and 52.5\% to 50\%; (iii) equalization of tax exemption of married and single individuals; (iv) extension of marital quotient to couples with a cohabiting contract. A linear taxation system is also modeled, with a negative income tax component. The slope is set to $50 \%$, and for the intercept, the value is set so as to obtain revenue neutrality as far as taxes and social security contributions are concerned. This leads to a yearly minimum guaranteed income of 2,900 euro per person.

\footnotetext{
${ }^{21}$ As mentioned in Footnote 6 the WFTC reform included a more generous treatment of childcare expenses for working families. This part of the reform in not modeled here. Initially take up of the childcare tax credit was very low, so excluding it from our analysis should not distort the results too strongly. However, with the signs of increases in the take up of childcare related credits it seems that any future analysis of the effect of tax credits on labor supply should account for childcare expenses and the related subsidies.

${ }^{22}$ For references see Vermeulen et al. (2006).
} 
The Belgian reform improves the bargaining position of a majority of women. Col lective labor supply reactions to the reform are moderate, with more than $90 \%$ of indi viduals retaining their baseline situation, both for men and women. When there is movement it is on average a slight decrease in labor supply. The linear taxation has an adverse effect on the bargaining position of most women, especially at lower levels. Here again, labor supply reactions are moderate when predicted with the collective model. Most changes concern people leaving the labor force as a consequence of the introduction of a relatively high minimum guaranteed income. According to the collective model, the reform is a Pareto improvement for about $30 \%$ of the households, disadvantages both spouses for some $20 \%$, and has conflicting impacts for $46 \%$. The reform increases overall inequality, leaving the concentration ratio almost unchanged.

\subsection{France}

Although, the French study concentrates on the man's negotiated utility rather than on the power index used in other studies (see Vermeulen et al., 2006, Section 3.3.1), it also reports the latter, and we focus on it here for ease of comparison. The calibrated power index for the man has a bimodal distribution, with modes at .35 and .84 , and it ranges over the whole $[0,1]$ interval. Variables with a significant impact in the prediction of the man's negotiated utility are the minimum utility level (corresponding to a dictatorial position for the wife) and interactions of the difference between maximum and minimum utility levels and the man's expected relative earning power $(+)$, the age difference (his minus her: + ), the difference in education level (his minus her: - ), the overall number of dependent children $(+)$, the number of older dependent children (aged 12 15:-), and the difference between unemployment rates relevant to each individual, depending on sex and education level (his minus her:-). Note that with a coefficient of 1 for minimum utility, this specification coincides exactly with a linear regression of the male's power index on the list of variables interacted with the utility range. Since the estimated coefficient is very close to 1 , comparability with the results from other studies is directly warranted. The baseline situation retained corresponds to calibrated values, but with retention of residuals from the estimation of the man's negotiated utility level, in order to trace changes to that magnitude as a consequence of the reform.

The specific reform studied for France consists in a tax credit for low wage earners, and its objectives are to provide incentives to work, and to subsidize low earnings. It is thus similar to the WFTC reform discussed above for the UK. Due to the importance of the inactivity trap, only $22 \%$ of the couples in the sample have a convex utility set.

Although, the Pareto frontier shifts towards the North East for about half of the households (efficiency effect) the final effect on the man's negotiated utility is negative on average: this is caused by a decrease in the expected relative earning capacity of half of the husbands (it increases for only $25 \%$ ).

The effects of the reform on labor supplies, as predicted by the collective model, are rather small, with only $5 \%$ of wives and $1 \%$ of husbands altering their labor supply. Note that about $10 \%$ of these are not recipients of the tax credit after the reform: this type of reaction is purely "collective", and is ruled out by the unitary setting.

\subsection{Germany}

Only $42 \%$ of the couples turn out to have a convex utility set. The calibrated male power index has a mean of 0.45 , and its significant determinants, in separate regressions for East 
and West Germany, are the woman's relative earning power at $40 \mathrm{~h}$ of work (-, with a larger absolute value in the West), and the age difference (her minus his: + , only in the West). The predicted male power index has a fairly stable mean of .45 in all situations, and its range is also stable, from about .27 to .53 .

Three reforms are considered:

i) The ongoing tax reform (henceforth "German tax reform') mainly concerns the tax rates applied: in this respect it is more generous than the baseline 1998 tax system, with the basic rate reduced to $15 \%$, from 7500 euro on, and the top rate to $42 \%$, from 5000 euro on. But the modeling here exaggerates the generosity of the reform by ignoring the suppression of various tax exemptions, for lack of the underlying information. Child benefits and allowances are increased.

ii) A move from joint to individual taxation is modeled on the basis of the 1998 tax schedule and existing benefits, with tax liabilities scaled down by the factor 0.95 in order to obtain overall tax neutrality, i.e. keeping fixed the net revenues of the state from the complete tax benefit system.

iii) A move to linear taxation, keeping joint taxation of couples. This is defined with a negative income tax of about 6,000 euro for singles and 9,600 euro for couples, and a (tax revenue neutral) constant marginal tax rate of $44.2 \%$. The reforms induce some important changes in the bargaining position of individuals. The German tax reform induces larger changes the lower the initial power index. Surprisingly, the move to individual taxation rather improves the men's bargaining position, especially at lower levels (the minimum goes up to .33 , and the dispersion is reduced). The smallest changes in the power index are obtained for the move to linear taxation, a surprising result since this is the most radical of the reforms considered.

The baseline situation corresponds to predictions obtained from the collective model under the current tax system, with the estimated power index and distinct recalibrated leisure interaction terms for each spouse. For the collective model, the participation rate of married females, initially of $71 \%$, decreases to $63 \%$ under the German tax reform, and to $53 \%$ under linear taxation, but goes up to $84 \%$ under individual taxation. Husbands react less to reforms than their wives do, and all reforms lead more to complementary changes in spouses' labor supplies than to substitution between the spouses.

The German tax reform has negative welfare effects for $23 \%$ of individuals in couples, with equal shares of men and women in this percentage. Overall the reform is more beneficial to women $(71 \%$ win) than to men $(53 \%)$. The collective model shows $66 \%$ Pareto winners, less than $1 \%$ of Pareto losers, and $22 \%$ of conflicting changes.

The collective model shows that for individual taxation the only decile of the distri bution of pre reform equivalent incomes in which a majority of women prefer the reform to the status quo is the highest decile. For men, there are some large gains and losses (measured in relative terms) at all deciles. There are only $3.5 \%$ Pareto winners, but $56 \%$ Pareto losers, and conflicting effects arise for $32 \%$ of the households.

For linear taxation, the results are given in Section 4.3 of Beninger et al. (2006).

\subsection{Italy}

In Italy, variables such as participation rate and wage level significantly differ by geo graphical location (the traditional distinction between North and South). It is to some extent surprising, thus, that location is insignificant in the male's power index regression. Among 
significant determinants of the male's power index are socio demographic variables such as his and her age $(-,+)$, his and her education $(+,-)$, an indicator for the absence of children $(-)$, and the relative expected earning power of the woman at 40 and $20 \mathrm{~h}(-,+)$.

In 2002, the government decided to introduce a reform of the income tax system aimed at lowering the tax liabilities. The 2002 tax benefit system retains the overall structure of the 1998 tax scheme: a piece wise linear tax system with 5 tax brackets. However relative to the 1998 tax system people with low to middle incomes pay less taxes because of changes which took effect before $2002 .^{23}$ The marginal tax rates range from 18 to $45 \%$. The latter is applied from the same threshold as in the 1998 system. On the benefit side, the child tax credit is increased substantially for families on low and middle incomes (an increase of about 200\%). The revenue neutral linear tax reform is characterized by a unique tax rate of $44 \%$ and a minimum guaranteed income of 3,000 euro for a single individual and 3,200 euro for each spouse in a married couple.

For both reforms considered, the power index varies for a majority of households in favor of the woman, except in families where the husband already has high bargaining power. The reforms considered seem to strengthen the leading position of the 'dominant' spouse in Italy. Thus, even though, the 2002 reform is beneficial for the whole population, the husbands have, on average, a lower consumption level than with the 1998 tax scheme, due to the change in the bargaining position in favor of the wives.

The normative analysis of the fiscal reforms shows redistribution effects in favor of the wives. Indeed, for the 2002 reform, while the majority of wives increase their welfare, most of the husbands lose out. In fact most couples are affected in conflicting ways by the reform: in almost $90 \%$ of the families, one spouse loses while the other gains, mostly in disfavor of the men $(83.4 \%)$. The simulated linear tax reform implies welfare gains for most women and welfare losses for most men. This can be related to the intrahousehold redistribution effect, which is mostly in favor of the wives.

\subsection{Spain}

The female's power index is positively and significantly influenced by the relative ex pected female earning power at $40 \mathrm{~h}$. Female participation and labor supply turn out to be negatively related to the female's power index: in households in which the wife has a high labor supply, she also tends to have a low power index. This finding, in a similar way to the counterintuitive results obtained in the UK power index regression, most likely relates to the fact that the methodology does not explicitly treat household production and considers all nonlabor time as 'pure' leisure.

The 1999 income tax reform simplified the 1994 tax system by eliminating most tax credits. Instead, it introduces a minimum family allowance, depending on the tax unit's demographic composition that is directly deductible from gross taxable income. A new piecewise linear tax schedule with only 6 tax brackets instead of 18 is introduced. The tariff applies now from the first euro of taxable income, but the tax allowance for employment income is raised and tax rates are considerably reduced with respect to previous years. There is a unique progressive tax schedule for both singles and couples but, as before the reform, couples are allowed to fill in either two separate income tax returns or a joint one.

Simulation of the 1999 reform using the collective model leads to a moderate increase in labor supplies, ranging from approximately $2 \%$ for married males to $17.5 \%$ for married

${ }^{23}$ These changes were introduced by the previous government. 
females. On average, the female's power index only slightly increases as a consequence of the reform, so that most of the change in labor supplies is due to changes in the budget constraint. Females in couples experience a larger increase in utility than males: $87.6 \%$ of females in the sample enjoy a utility increase, as opposed to $29.6 \%$ of males.

\subsection{Summary}

First note that the absolute values of power indices may not readily be compared across countries or even across households, since these values depend on the form of the Pareto frontier. However, what can easily be compared across countries are the determinants of the bargaining position. Starting with the variables that are directly connected with the collective framework, the distribution factors mentioned in Section 3.2.1, consider first the original 'earning potential' variables introduced in the methodology of Vermeulen et al. (2006). Without exception, these come up as significant determinants, with the expected sign: a higher earning power improves one's bargaining position. An additional variable considered only in the UK study is the ratio of unearned income of the woman to overall family income at the $400 \mathrm{~h}$ combination, and it also has the expected sign. These con verging results are encouraging for the collective approach. Two other encouraging results are that the 'difference in unemployment rates' is significant in the French study, and that the UK study also finds a positive effect on his power index when he has the higher potential gross wage (even if he does not work).

Concerning the effect of age on bargaining power, for Germany we find that the hus band's bargaining power is positively influenced by the difference between his and her age (his minus her, as for all differences mentioned in this paragraph), but for France and the UK his power is negatively influenced by the age difference. For Italy, the conclusion emerges that both spouses become more lenient with age. Difference in individual un earned incomes in Belgium has a positive impact on his power index. For education, geographical location, and for the effect of the presence and number of children in different age groups, results are mixed, and cannot be easily summarized. It is worth noting that for variables which are not distribution factors, that is variables that may also have an impact on either preferences or the budget constraint, there is no reason to expect convergence, since we have no a priori opinion on the signs of the coefficients, and there may also be identification issues concerning these.

\section{Conclusion}

Despite a very important theoretical advancement in the modeling of labor supply of individuals in couples in the recent decade, the collective model has found little empirical application. The difficulties of accounting for nonparticipation, nonconvex budget sets and children have been most important problems of the collective framework which favored the unitary model in practical application for the purpose of fiscal reform analysis. This paper confirms that efforts made in the cause of further development of multi person household models are well worth it and that more work ought to be done to extend their application.

We generated a data set underlined by a fully deterministic model with features of the collective framework, in which individuals make optimal decisions subject to the house hold budget constraint and their bargaining power within the couple. The decision process is assumed to be efficient so that the optimum is on the Pareto frontier. The precise point on the frontier which is chosen depends on the relative bargaining power of the members of 
the couple. The data set has been created in part by the estimation of preferences for single individuals, which were used for individuals in couples, and in part by the calibration of parameters specific to individuals in couples. This methodology allowed us to account for nonparticipation and nonconvex budget sets and to include couples with children in our "collective" model. ${ }^{24}$

Two results of our study deserve special attention. First of all, among significant determinants of the bargaining power in couples, we found several relating to the earning potential of partners. In the UK study, the effects of two distribution factors relating to the tax and benefit system have the expected signs and are statistically significant. It is important to note that in all studies for other European countries, which we summarized in Section 6 the coefficients on distribution factors are statistically significant and have the expected sign. This finding is of great importance given that this dependency is a crucial feature of the collective model.

Another important result is that if indeed decisions in couples are taken in some form of "collective" fashion then the question of who receives government transfers does matter for individual behavior. We presented the results of simulations of two different forms of the introduction of the Working Families' Tax Credit, which became part of the UK tax and benefit system in October 1999. One form of WFTC assumed that the benefit was paid to the main carer, while the other assumed that it was paid to the main earner in the couple. Although whether the WFTC is paid to the mother or to the father does not change the household budget constraint, we showed that the collective framework can account for differences in behavioral responses between these two forms of the reform. To our knowledge, our paper is the first attempt to model this specific element of the WFTC reform.

Acknowledgements This paper exploits work done in the 1 year project "Welfare analysis of fiscal and social reforms in Europe: does the representation of the family decision process matter?', partly financed by the EU, General Directorate Employment and Social Affairs, under grant VS/200/0778. We are grateful for comments and advice from the Editors, an anonymous referee, Martin Browning, Pierre André Chiappori, Costas Meghir and Howard Reed. It would have been difficult to complete the project so quickly without Ian Walker's UK tax and benefit program for Stata. Financial support from the Economic and Social Research Council is greatly appreciated. The usual disclaimer applies.

\section{Appendix}

A Personal income taxation in the UK

Table A1 Income tax and National Insurance in 1998/99 values in euro in parentheses

\begin{tabular}{ll}
\hline Income tax bands: (individual annual income) & \multicolumn{1}{c}{ Applicable rate } \\
First $£ 4,195(€ 6,090)$ & $0 \%$ \\
Next $£ 4,300(€ 6,250)$ & $20 \%$ \\
Next $£ 22,800(€ 33,100)$ & $23 \%$ \\
Above $£ 31,295(€ 45,450)$ & $40 \%$ \\
Credit for couples: $£ 285(€ 410)$ & \\
National Insurance bands: (individual weekly income) & $0 \%$ \\
$£ 0 £ 64 *(€ 93)$ & $10 \%$ \\
$£ 65 £ 485(€ 93 € 704)$ &
\end{tabular}

Notes: $*$ There is a $2 \%$ fee on reaching $£ 64$ per week

${ }^{24}$ Note, however, that children in our model are not taken up in a structural way. A more structural model accounting for expenditure on children is presented in Blundell, Chiappori, and Meghir (2005). 


\section{B Family Credit vs. Working Families' Tax Credit}

Table A2 shows the difference in values of credits and applicable amounts between Family Credit in April 1998 and WFTC in June 2001. The latter include several additional reforms since the introduction of the WFTC in October 1999 which further increased the generosity of payments.

Table A2 Family Credit and Working Families' Tax Credit values in euro in parentheses

\begin{tabular}{lll}
\hline & Family Credit $(1998)$ & Working Families’ Tax Credit (2001 in 1998 prices) \\
\hline Applicable amount & $£ 79.00(€ 114.75)$ & $£ 88.20(€ 128.10)$ \\
Basic credit & $£ 48.80(€ 70.90)$ & $£ 56.00(€ 81.35)$ \\
Full time premium & $£ 10.80(€ 15.70)$ & $£ 10.80(€ 15.70)$ \\
Child credits & & \\
0 10 years old & $£ 12.35(€ 17.95)$ & $£ 24.70(€ 35.90)$ \\
11 15 years old & $£ 20.45(€ 29.70)$ & $£ 24.70(€ 35.90)$ \\
1618 years old & $£ 25.40(€ 36.90)$ & $£ 25.40(€ 36.90)$ \\
Withdrawal taper & $70 \%$ & $55 \%$ \\
\hline
\end{tabular}

\section{Estimating preferences of single individuals}

Table A3 presents estimates of utility function parameters for single individuals. These parameters are used for individuals in couples in the calibration exercise presented in this paper. The estimation was conducted using the random parameter logit model taking the utility function to be of the LES type.

Table A3 Estimation of preferences for single women

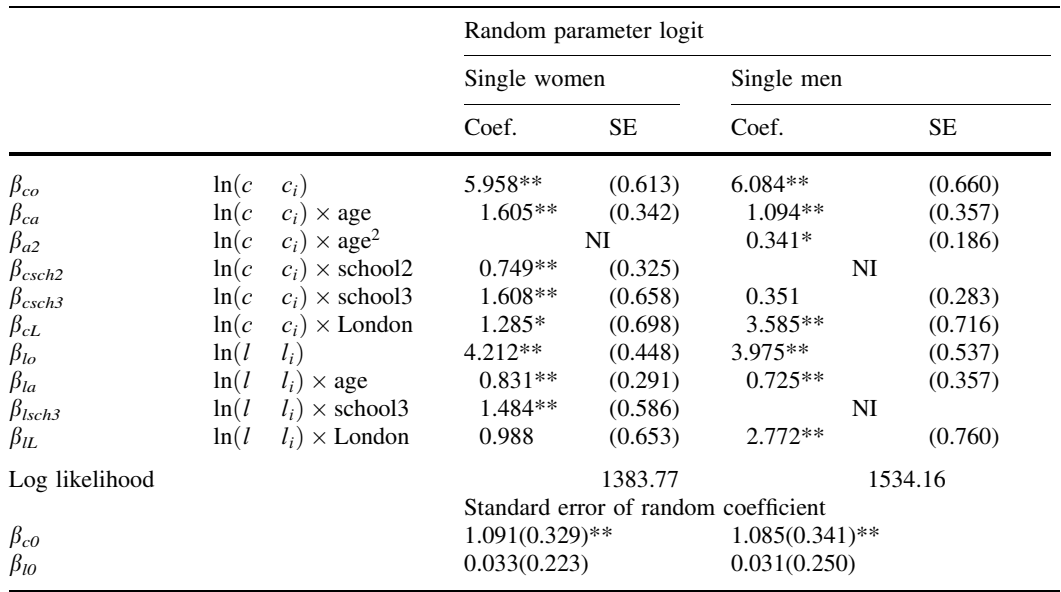

Notes: Education variables: school2 dummy for leaving full time education aged 17 or 18; school3 dummy for leaving full time education aged 19 and over; London a regional dummy for London. Only variables significant in simple conditional logit estimates were included in the random parameter logit estimations; NI 'not included' the variable was not significant in the conditional logit estimations 
The minimum level of leisure in the utility function $\left(l_{i}\right)$ was derived from information from the National Statistics Omnibus Survey time use module (May, 1999), while for the minimum level of consumption $\left(c_{i}\right)$ we used information from the FRS. The latter was done in two stages. First we calculated $c_{\text {min }}$, the overall minimum level of disposable income over available hours choices for the whole sample. Because $\left(\begin{array}{ll}c & c\end{array}\right)$ must be positive, the value of $c$ had to be less than the value of the possible minimum level of disposable income $c_{\text {min }}$. We found this difference $\left(c_{0}\right)$ using a grid search over various levels of $c_{0}<0$, such that $c \quad c_{\text {min }}+c_{0}$. The grid search based on the value of log like lihood in estimation of preferences produced values for $c_{0}$ equal to $£ 33.30$ per week for men and $£ 16.50$ per week for women. In the calibrations for couples $l_{i}$ was also based on the National Statistics Omnibus Survey. The minimum consumption levels for men and women were kept at the same level as for singles in the case of couples without children. For couples with children the minimum values of consumption were increased to take account of the universal Child Benefit payments.

D Family Resources Survey data, 1998/99

Table A4 Samples of singles and couples summary statistics

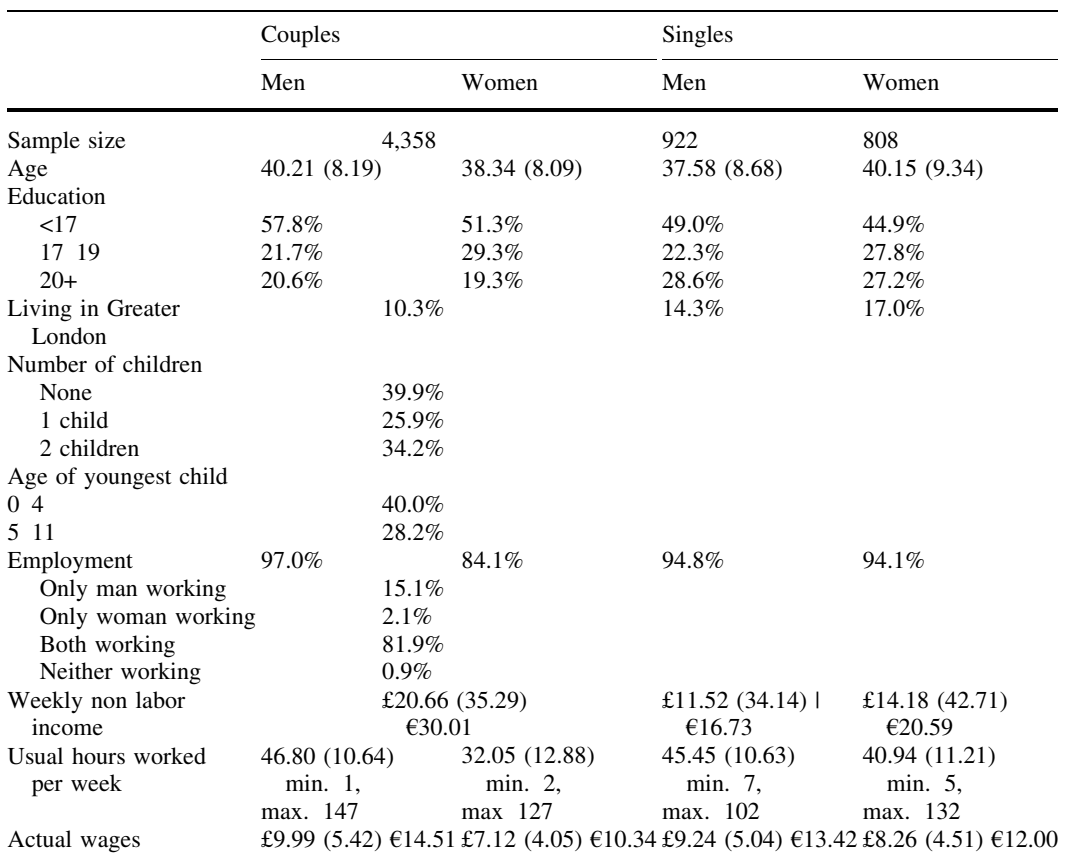

Notes: Based on Family Resources Survey 1998/99 data. Actual wages conditional on wages being reported; usual hours worked per week (including overtime) conditional on employment; education groups by age when individuals left full time education. For age, weekly non labor income, usual hours worked per week, the first figure is the average over the sample and the figure in parenthesis is the standard deviation 


\section{References}

Adam, S., \& Kaplan, G. (2002). A survey of the UK tax system. IFS Briefing Note no. 9. http://www.if s.org.uk/taxsystem/taxsurvey.pdf.

Blundell, R., \& Walker, I. (1986). A life cycle consistent empirical model of family labor supply using cross section data. Review of Economic Studies, 53, 539558.

Blundell, R., Chiappori, P A., \& Meghir, C. (2005). Collective Labor Supply with Children. Journal of Political Economy, 113, 12771306.

Blundell, R., Lechene, V., \& Myck, M. (2002). Tax credit reforms and labour supply in a collective model. Mimeo. London: IFS.

Blundell R., Duncan A., McCrae J., \& Meghir C. (2000). The labour market impact of the working families' tax credit. Fiscal Studies, 21, 6574.

Bourguignon, F., Browning, M., Chiappori, P A., \& Lechene, V. (1993). Intra household allocation and consumption: a model and some evidence from French data. Annales d'Économie et de Statistique, 29, 137156.

Brewer, M. (2003). The new tax credits. IFS Briefing Note No. 35. London: IFS. http://www.ifs.org.uk/ taxben/bn35.pdf.

Brewer, M., Clark, T., \& Wakefield, M. (2002). Five Years of Social Security Reform in the UK." IFS Working Paper no. 12/02. London: IFS.

Chiappori, P A. (1992). Collective labor supply and welfare. Journal of Political Economy, 100, 437467.

Department for Work and Pensions. (2001). 'Income Related Benefits: Estimates of Take up: 1998/99.', London: Department of Work and Pensions. http://www.dwp.gov.uk/.

Gregg, P., Johnson, P., \& Reed, H. (1999). Entering work and the british tax and benefit system. London: IFS.

Inland Revenue (2002). Working Families' Tax Credit Quarterly Enquiry. London: Inland Revenue.

Kaplan, G., \& Leicester, A. (2002). A Survey of the UK Benefit System. IFS Briefing Note no. 13. London: IFS.

Lundberg, S., \& Pollak, R. A. (1996). Bargaining and distribution in marriage. Journal of Economic Perspectives, 10, 139158.

Myck, M. (2000). Fiscal Reforms Since May 1997. IFS Briefing Note no. 14. London: IFS.

Van Soest, A. (1995). Structural models of family labor supply. A discrete choice approach. Journal of Human Resources, 30, 6388.

Vermeulen, F., Bargain, O., Beninger, D., Beblo, M., Blundell, R., Chiuri, M C., Carrasco, R., Laisney, F., Lechene, V., Moreau, N., Myck, M., \& Ruiz Castillo, J. (2006). Collective models of household labor supply with nonconvex budget sets and nonparticipation: a calibration approach. Review of Economics of the Household, 4, 113127. 